\title{
Thyroid transcription factor-1 distinguishes subependymal giant cell astrocytoma from its mimics and supports its cell origin from the progenitor cells in the medial ganglionic eminence
}

\author{
Jen-Fan Hang ${ }^{1,2}$, Chih-Yi Hsu ${ }^{1,2}$, Shih-Chieh Lin ${ }^{1,2}$, Chih-Chun Wu ${ }^{3}$, Han-Jui Lee ${ }^{3}$ and \\ Donald Ming-Tak Ho ${ }^{1,2}$ \\ ${ }^{1}$ Department of Pathology and Laboratory Medicine, Taipei Veterans General Hospital, Taipei, Taiwan; \\ ${ }^{2}$ School of Medicine, National Yang-Ming University, Taipei, Taiwan and ${ }^{3}$ Department of Radiology, \\ Taipei Veterans General Hospital, Taipei, Taiwan
}

\begin{abstract}
Subependymal giant cell astrocytoma is a benign brain tumor mostly associated with tuberous sclerosis complex. However, it may be misinterpreted as other high-grade brain tumors due to the presence of large tumor cells with conspicuous pleomorphism and occasional atypical features, such as tumor necrosis and endothelial proliferation. In this study, we first investigated thyroid transcription factor-1 (TTF-1) expression in a large series of subependymal giant cell astrocytomas and other histologic and locational mimics to validate the diagnostic utility of this marker. We then examined TTF-1 expression in non-neoplastic brain tissue to determine the cell origin of subependymal giant cell astrocytoma. Twenty-four subependymal giant cell astrocytoma specimens were subjected to tissue microarray construction. For comparison, a selection of tumors, including histologic mimics (21 gemistocytic astrocytomas and 24 gangliogliomas), tumors predominantly occurring at the ventricular system (50 ependymomas, 19 neurocytomas, and 7 subependymomas), and 134 astrocytomas (3 pleomorphic xanthoastrocytomas, 45 diffuse astrocytomas, 46 anaplastic astrocytomas, and 40 glioblastomas) were used. Immunohistochemical stain for TTF-1 was positive in all 24 subependymal giant cell astrocytomas, whereas negative in all astrocytomas, gangliogliomas, ependymomas, and subependymomas. Neurocytomas were positive for TTF-1 in 4/19 (21\%) of cases using clone $8 \mathrm{G} 7 \mathrm{G} 3 / 1$ and in $9 / 19(47 \%)$ of cases using clone SPT24. In the three fetal brains that we examined, TTF-1 expression was seen in the medial ganglionic eminence, a transient fetal structure between the caudate nucleus and the thalami. There was no BRAF ${ }^{V 600 E}$ mutation identified by direct sequencing in the 20 subependymal giant cell astrocytomas that we studied. In conclusion, TTF-1 is a useful marker in distinguishing subependymal giant cell astrocytoma from its mimics. Expression of TTF-1 in the fetal medial ganglionic eminence indicates that subependymal giant cell astrocytoma may originate from the progenitor cells in this region.
\end{abstract}

Modern Pathology (2017) 30, 318-328; doi:10.1038/modpathol.2016.205; published online 2 December 2016

Subependymal giant cell astrocytoma is a benign brain tumor most commonly associated with familial syndrome of tuberous sclerosis complex, which is characterized by germline mutation of TSC1 or TSC2

Correspondence: Professor DM-T Ho, MD, FCAP, Department of Pathology and Laboratory Medicine, Taipei Veterans General Hospital, No. 201, Section 2, Shipai Road, Taipei 11217, Taiwan. E-mail: mtho@vghtpe.gov.tw

Received 14 July 2016; revised 18 October 2016; accepted 19 October 2016; published online 2 December 2016 gene. Non-syndromic tumor is rare, but has been reported in up to $60 \%$ of cases in a surgical series. ${ }^{1}$ The tumor most commonly occurs in the first two decades of life and typically arises from the caudothalamic groove adjacent to the foramen of Monro. ${ }^{2,3}$ Making the correct diagnosis of subependymal giant cell astrocytoma is highly relevant because it is one of the major diagnostic criteria for tuberous sclerosis complex. ${ }^{4}$ In addition, due to its slowly growing nature, patients with subependymal giant cell astrocytoma are precluded from further 
aggressive treatment such as chemo- and radiotherapy, which are often applied to patients with higher-grade gliomas. Finally, patients with subependymal giant cell astrocytoma may benefit from specific targeted therapies such as mammalian target of rapamycin (mTOR) inhibitors. ${ }^{5}$ Pathological diagnosis of subependymal giant cell astrocytoma is usually straightforward when the patient presents with typical clinical and radiological features. However, morphologically, due to the presence of large epithelioid to spindle tumor cells with conspicuous pleomorphism and occasional presence of atypical features, such as tumor necrosis and endothelial proliferation, subependymal giant cell astrocytoma may potentially be misinterpreted as other higher-grade brain tumors, especially for surgical pathologists inexperienced in brain tumor diagnosis. $1,6,7$

Immunohistochemically, subependymal giant cell astrocytoma frequently shows co-expression of glial and neuronal markers. However, the staining consistency of these markers varies in different studies and most of them stain in a patchy and focal fashion. ${ }^{1,8-13}$ Furthermore, these markers are not specific for subependymal giant cell astrocytoma and can be expressed in a variety of brain tumors. Therefore, most of the glial and neuronal markers have a limited role in pathological diagnosis. Recently, diffuse nuclear expression of thyroid transcription factor-1 (TTF-1) has been reported in two small series of subependymal giant cell astrocytomas and may serve as an ancillary marker. ${ }^{14,15}$ However, the case number of these two studies was small and comparison with other glial and glioneuronal tumors was not available.

The $B R A F^{\mathrm{V} 600 \mathrm{E}}$ mutation has been reported in several low-grade pediatric glioneuronal tumors, such as pleomorphic xanthoastrocytomas, gangliogliomas, and dysembryoplastic neuroepithelial tumors, and its association with activation of mTOR signaling pathway in these tumors has been documented. ${ }^{16-18}$ Interestingly, the $B R A F^{\mathrm{V} 600 \mathrm{E}}$ mutation has also been reported in 1 out of 3 and 6 out of 14 subependymal giant cell astrocytomas in two recent studies. ${ }^{16,19}$

In the current study, we investigated TTF-1 expression by immunohistochemistry in a large series of subependymal giant cell astrocytomas as well as a collection of histologic and locational mimics to validate its utility as a diagnostic marker. Moreover, we examined TTF-1 expression in non-neoplastic fetal and adult brain tissues. Combining the radiological findings, we attempted to determine the cell origin of subependymal giant cell astrocytoma. The mutation status of the $B R A F$ gene in our series of subependymal giant cell astrocytomas was also studied.

\section{Materials and methods}

\section{Case Selection and Pathological Review}

This study was approved by the institutional review board of Taipei Veterans General Hospital (VGHIRB No.:2015-06-006BC). A total of 22 subependymal giant cell astrocytoma patients who underwent craniotomy and tumor removal were identified from the medical records of Taipei Veterans General Hospital during the period of 1995 to 2013. Among them, four patients had two operations. Clinical information, including age, gender, and status of tuberous sclerosis complex was obtained from the medical charts. Nineteen cases had available preoperative neuroimages for the review of location and size of the tumor, as well as other central nervous system (CNS) signs of tuberous sclerosis complex. Postoperative follow-up images were available in 17 patients. All the original slides of the 26 specimens were retrieved from the surgical pathology archive for diagnosis confirmation and detailed microscopic review. Twenty-four specimens, including 22 primary and 2 recurrent tumors, had sufficient formalin-fixed paraffin-embedded tumor tissues for tissue microarray construction using MTA Booster OI manual tissue arrayer (Alphelys, Plaisir, France). Two tissue cores (core diameter: $2.0 \mathrm{~mm}$ ) were obtained from the tumor area in each case. For comparison, tissue microarrays of a selection of brain tumors, including histologic mimics (21 gemistocytic astrocytomas and 24 gangliogliomas), tumors predominantly occurring at the ventricular system (50 ependymomas, 19 neurocytomas, and 7 subependymomas) and 134 astrocytomas (3 pleomorphic xanthoastrocytomas, 45 diffuse astrocytomas, 46 anaplastic astrocytomas, and 40 glioblastomas), were also constructed using the same method. In addition, formalin-fixed paraffin-embedded blocks of three adult autopsy cases (age: 27, 38, and 53 years) and three fetuses of spontaneous abortion (gestational age: 9,11 , and 11 weeks) were studied to determine the TTF-1 expression in the non-neoplastic brains.

\section{Immunohistochemistry and Interpretation}

Immunohistochemical stains were performed on

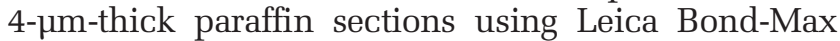
autostainer (Leica Microsystems, Germany). The automated program for immunohistochemistry included deparaffinization using Bond Dewax Solution, antigen retrieval with Bond ER2 solution (EDTA, pH 9) at $100{ }^{\circ} \mathrm{C}$ for $30 \mathrm{~min}$, incubation with primary antibodies at room temperature for $15 \mathrm{~min}$, and visualization using Bond Polymer Refine Detection kit. The following primary antibodies were used, including antiTTF-1 (clone 8G7G3/1, 1:300 dilution, Dako, Denmark and clone SPT24, 1:200, Leica Microsystems), antiglial fibrillary acidic protein (GFAP, clone GF2, 1:300, Dako), anti-synaptophysin (clone SY38, 1:50, Leica Microsystems), anti-neurofilament (clone 2F11, 1:100, 
Dako), and anti-NeuN (clone A60, 1:1000, Millipore, USA). Immunohistochemistry for all the primary antibodies were carried out on the tissue microarray of subependymal giant cell astrocytoma. Both clones of anti-TTF-1 were applied on the tissue microarrays of other brain tumors and clone 8G7G3/1 was applied on the non-neoplastic brain tissues.

The intensity of nuclear staining of TTF-1 was scored and recorded. We screened all sections at $\times 40$ low power field ( $\times 4$ objective and $\times 10$ ocular lenses) under light microscope. A case without nuclear staining was scored as negative. Those uncertain for nuclear staining at $\times 40$ field but with definite nuclear staining at higher magnification were scored as weak. Those with definite nuclear staining at $\times 40$ field were scored as either moderate or strong, depending on staining intensity.

\section{DNA Extraction and Direct Sequencing of $B R A F^{600}$}

The representative tumor area with more than $70 \%$ tumor cells was marked on one H\&E slide of each 24 subependymal giant cell astrocytoma specimens. The corresponding 10- $\mu$ m-thick sections of formalin-fixed paraffin-embedded tissues were deparaffinized using xylene and washed in ethanol. The selected tumor area was microdissected manually and subjected to DNA extraction using the PicoPure DNA extraction kit (Arcturus/Applied Biosystems, USA). The concentration of the extracted DNA was quantified by Nanodrop 2000 (Thermo Fisher Scientific, USA). The DNA samples were subjected for BRAF exon 15 analysis using polymerase chain reaction (PCR) and direct sequencing method as previously described. ${ }^{20}$ The sequencing data was analyzed using Mutation Surveyor software (SoftGenetics, USA).

\section{Results}

\section{Clinicoradiological Summary and Histologic Review}

The 22 subependymal giant cell astrocytoma patients were equally distributed in gender (male: female $=1: 1$ ) with a mean age of 10.8 years (range: 8 months to 26 years). Nineteen cases with preoperative neuroimages showed 9 left ventricular tumors, 7 right ventricular tumors, and 3 bilateral ventricular tumors. All the tumors arose from the region of caudothalamic groove. The tumor size ranged from 1 to $7 \mathrm{~cm}$ (mean: $3.4 \mathrm{~cm}$ ). Among these patients, 19/22 (86.4\%) had clinical evidence of tuberous sclerosis complex. Four patients had two operations. Two of them were due to residual tumors (cases S15 and S20) after incomplete excisions, whereas the other two were due to tumor recurrence 3 and 2 years after the first surgery (cases S1 and S10, respectively). The clinical features, radiological findings, and follow-up information of the patients with subependymal giant cell astrocytoma are summarized in Table 1.

For the microscopic review, all the subependymal giant cell astrocytoma specimens, including 22 primary tumors, 2 second excisions of the residual tumors, and 2 recurrent tumors, showed tumors composed of three types of tumor cells in various

Table 1 Clinical and radiological summary of patients with subependymal giant cell astocytoma

\begin{tabular}{|c|c|c|c|c|c|c|c|c|}
\hline No & Age (years) & Gender & Site & Location & Size $(\mathrm{cm})$ & TSC & CNS signs of TSC & Radiological follow-up (years) \\
\hline S1 & 6 & $\mathrm{M}$ & LVL & CTG & 6.2 & - & - & RTS after second OP (11.7) \\
\hline S2 & 7 & $\mathrm{~F}$ & LVB & CTG & 4.9(R), 1.6(L) & + & T, SEN & NRT (14.4) \\
\hline S3 & 7 & $\mathrm{M}$ & NA & NA & NA & NA & NA & NA \\
\hline S4 & 7 & $\mathrm{~F}$ & LVR & CTG & 7 & + & $\mathrm{T}, \mathrm{SEN}$ & NA \\
\hline S5 & 11 & $\mathrm{~F}$ & LVR & CTG & 1.2 & + & $\mathrm{T}, \mathrm{SEN}$ & NRT (0.7) \\
\hline S6 & 12 & M & NA & NA & NA & + & $\mathrm{T}, \mathrm{SEN}$ & NA \\
\hline S7 & 12 & $\mathrm{M}$ & LVL & CTG & 2 & + & $\mathrm{T}, \mathrm{SEN}$ & RTS (6.1) \\
\hline S8 & 13 & $\mathrm{~F}$ & LVR & CTG & NA & + & SEN & NA \\
\hline S9 & 12 & M & LVL & CTG & 5.4 & + & $\mathrm{T}, \mathrm{SEN}$ & RTS (0.3) \\
\hline S10 & 6 & M & LVR & CTG & 3.5 & + & T, SEN & NRT after second OP (11.5) \\
\hline S11 & 8 & M & LVR & CTG & 2.2 & + & $\mathrm{T}, \mathrm{SEN}$ & NRT (5) \\
\hline $\mathrm{S} 12$ & 26 & $\mathrm{~F}$ & LVB & CTG & 1 (R), 1 (L) & + & $\mathrm{T}, \mathrm{SEN}$ & RTS (2.3) \\
\hline S13 & 7 & $\mathrm{~F}$ & NA & NA & NA & + & $\mathrm{T}, \mathrm{SEN}$ & NRT (0.2) \\
\hline S14 & 9 & $\mathrm{M}$ & LVL & CTG & 2.4 & + & $\mathrm{T}, \mathrm{SEN}$ & NRT (0.3) \\
\hline S15 & 16 & $\mathrm{~F}$ & LVR & CTG & 3.9 & + & $\mathrm{T}, \mathrm{SEN}$ & NRT after second OP (7.1) \\
\hline S16 & 11 & M & LVB & CTG & 2 (R), $2.7(\mathrm{~L})$ & + & $\mathrm{T}, \mathrm{SEN}$ & RTS (1) \\
\hline S17 & 12 & $\mathrm{~F}$ & LVL & CTG & 4.4 & + & $\mathrm{T}, \mathrm{SEN}$ & RTS (1.9) \\
\hline S18 & 8 & $\mathrm{~F}$ & LVL & CTG & 5.3 & + & $\mathrm{T}, \mathrm{SEN}$ & $\mathrm{TR}, 4.6 \mathrm{~cm}(5.4)$ \\
\hline S19 & 0.7 & $\mathrm{~F}$ & LVL & CTG & 2.5 & + & $\mathrm{T}, \mathrm{SEN}$ & NTR (4.4) \\
\hline S20 & 15 & $\mathrm{M}$ & LVL & CTG & 3.8 & - & - & RTS after second OP (3.8) \\
\hline S21 & 9 & $\mathrm{M}$ & LVL & CTG & 4.1 & - & - & NTR (4) \\
\hline S22 & 22 & $\mathrm{~F}$ & LVR & CTG & 2.3 & + & SEN & NA \\
\hline
\end{tabular}

Abbreviations: CNS, central nervous system; LVL, lateral ventricle, left; LVB, lateral ventricle, bilateral; LVR, lateral ventricle, right; CTG, caudothalamic groove; R, right; L, left; +, present; -, absent; NA, not available; T, cortical tubers; SEN, subependymal nodules; RTS, residual tumor with stable condition; NRT, no residual or recurrent tumor; TR, tumor recurrence; OP, operation. 

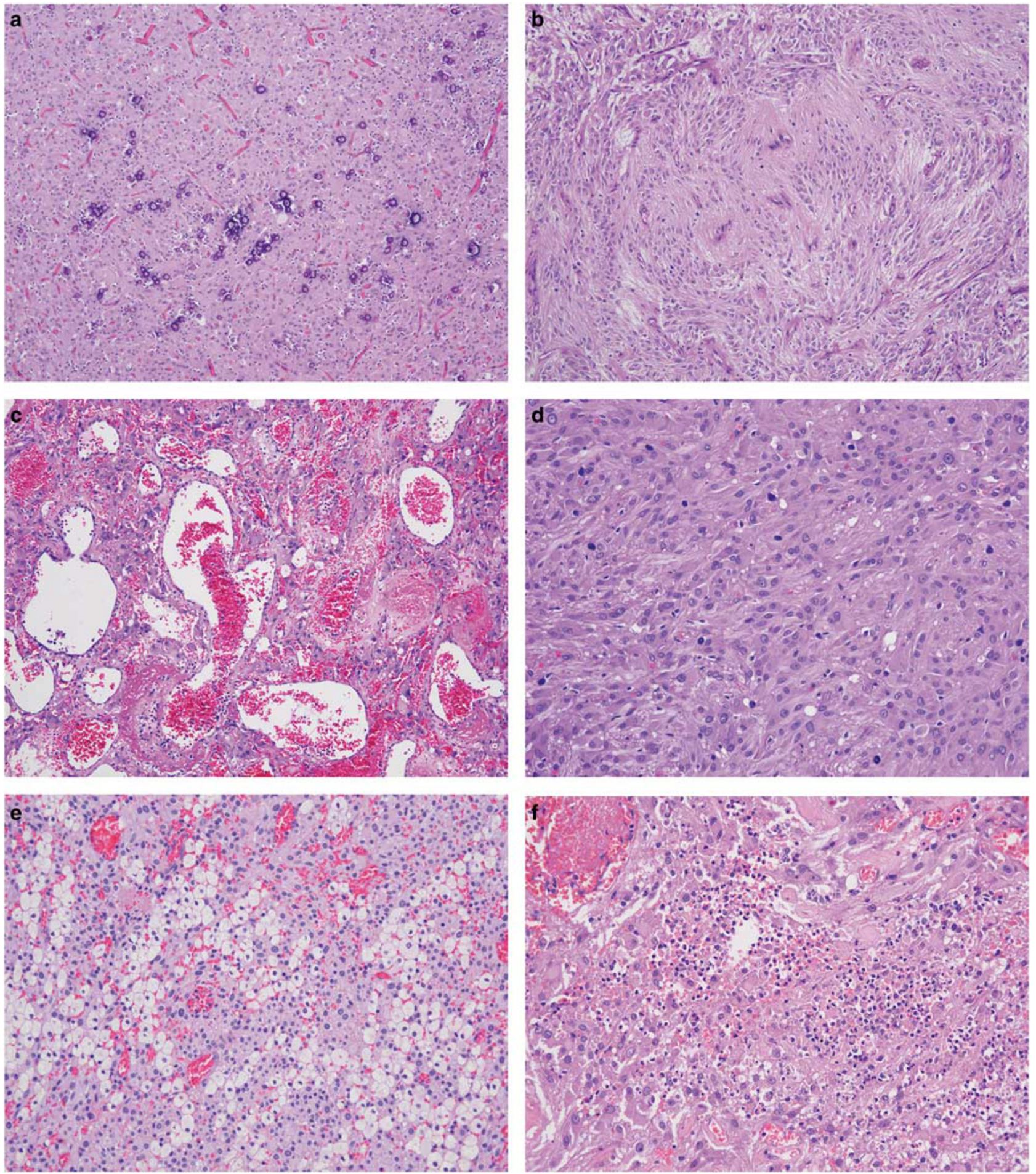

Figure 1 Histological pictures of subependymal giant cell astrocytomas show chicken wire vessels and psammomatous calcification (a), perivascular pseudorosettes (b), angiomatous pattern (c), mast cell infiltration (d), xanthoma cell aggregation (e), and tumor necrosis (f). The tumors are composed of gemistocyte-like cells (a and e) and spindle cells (b and $\mathbf{d})$ in various proportions. H\&E. Original magnification: $\times 100$ in $(\mathbf{a}-\mathbf{c}) ; \times 200$ in $(\mathbf{d}-\mathbf{f})$.

proportions, including (i) gemistocyte-like cells with plump, glassy cytoplasm, and eccentric nuclei (Figures 1a and e), (ii) ganglion-like giant cells with distinct nuclei and occasional bi- or multi-nucleation, nuclear pseudoinclusion, and perimembranous Nissl-like basophilic substance (Figure 2e), and (iii) spindle cells (Figures $1 \mathrm{~b}$ and $\mathrm{d}$ ). The mitotic activity was rare or absent. The histologic patterns are shown 

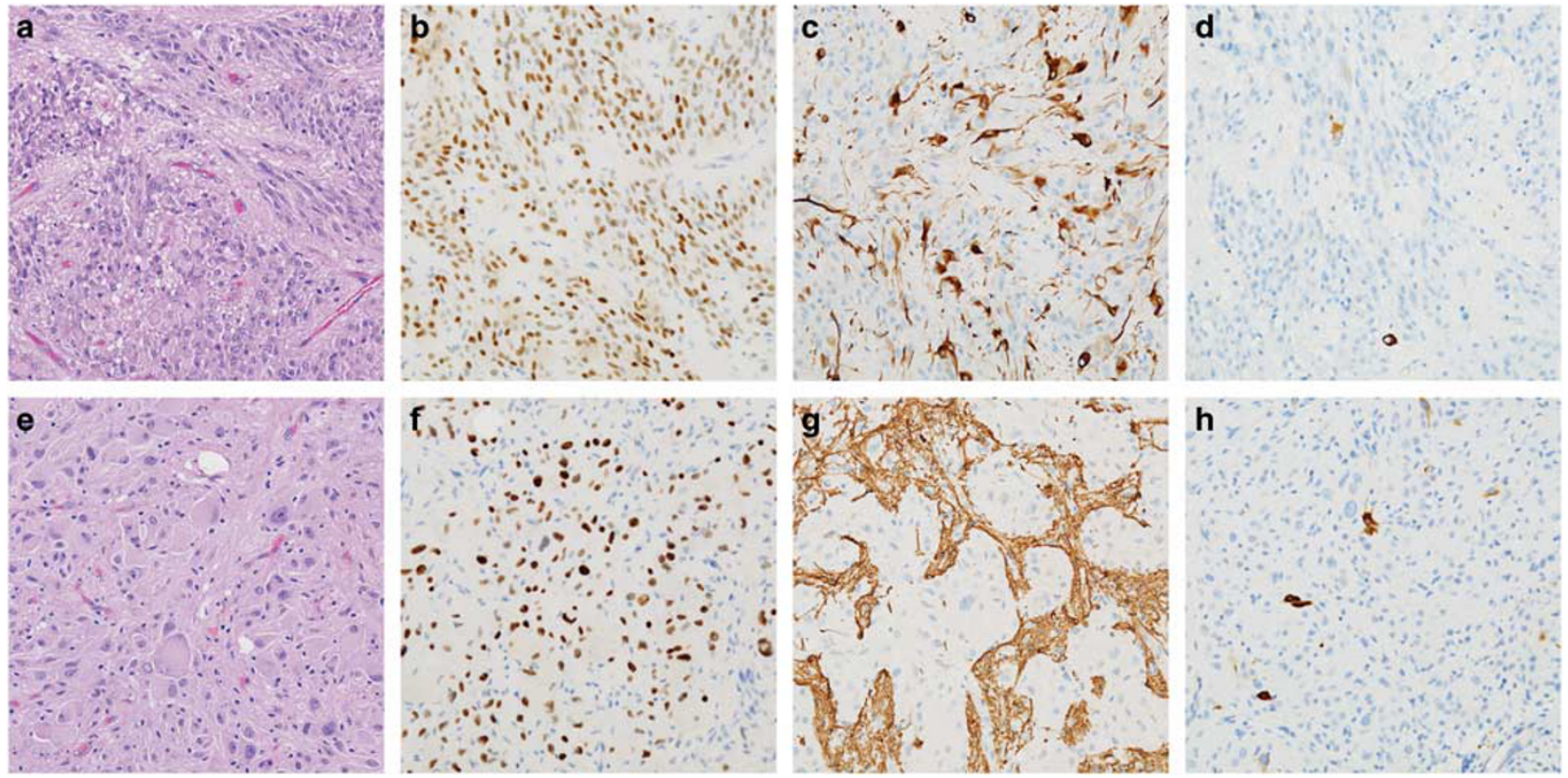

Figure 2 The immunohistochemical study of case S8 (a-d) and case S21 (e-h). The ganglion-like giant cells is conspicuous in case S21 (e). Both cases show diffuse moderate to strong nuclear expression of TTF-1 (b and $\mathbf{f}$ ). The tumor cells are focally positive for GFAP in case S8 (c). In case S21, staining for GFAP demonstrates only the entrapped reactive glial tissue. The tumor cells are non-reactive for GFAP (g). There are scattered tumor cells reactive for synaptophysin (d) or neurofilament (h). Original magnification: $\times 200$.

in Figure 1, which includes: chicken wire vessels $(15 / 26$ cases, 58\%), perivascular pseudorosettes $(11 / 26,42 \%)$, psammomatous calcification (10/26, $38 \%)$, angiomatous pattern (7/26, 27\%), lymphocytic infiltration $(7 / 26,27 \%)$, tumor necrosis $(4 / 26,15 \%)$, mast cell infiltration (4/26, 15\%), and xanthoma cell aggregation (3/26, 12\%). The histologic patterns of the two residual tumors from second excision were largely similar to the first specimens. Of the recurrent tumors, necrosis was seen in both primary and recurrent tumors of case S10, whereas no atypical feature was noted for both tumors of case S1.

\section{Immmunohistochemical Results of Subependymal Giant Cell Astrocytoma and Mimics}

Among the 24 subependymal giant cell astrocytoma specimens, including 22 primary and 2 recurrent tumors, there were $13(54 \%)$ reactive for GFAP, 5 $(21 \%)$ reactive for synaptophysin, $5(21 \%)$ reactive for neurofilament, and none for NeuN. Unlike the usual diffuse staining pattern in diffuse astrocytomas, the staining pattern of GFAP in subependymal giant cell astrocytoma was mostly focal (Figure 2c). For cases non-reactive for GFAP, some entrapped glial tissues were commonly found (Figure 2f). In cases reactive for neurofilament or synaptophysin, only scattered tumor cells were demonstrated by these stains (Figures $2 \mathrm{~d}$ and h). Staining for GFAP highlighted more spindle cells, whereas staining for neurofilament or synaptophysin demonstrated mostly plump and epithelioid cells. The immunohistochemical studies of the glial and neuronal markers in subependymal giant cell astrocytoma in the literature are summarized in Table 2.

The results of immunohistochemistry for TTF-1 using two different clones of antibodies are shown in Table 3 . All 24 subependymal giant cell astrocytomas showed diffuse nuclear expression of TTF-1 with moderate to strong intensity (Figures 2b and f; 3a). Neurocytomas were diffusely positive for TTF-1 in 4/19 (21\%) of cases using clone $8 \mathrm{G} 7 \mathrm{G} 3 / 1$ and in 9/19 (47\%) of cases using clone SPT24. The staining intensities were mostly weak to moderate (Figure 3b). Astrocytomas, gangliogliomas, ependymomas, and subependymomas were all negative for TTF-1 (Figures $3 \mathrm{c}-\mathrm{f})$.

\section{TTF-1 Expression in Non-Neoplastic Brain Tissues}

TTF-1 expression was seen in the ependymal cells and subependymal progenitor cells in the medial ganglionic eminence in all three fetal brains (Figure 4). The TTF-1 stained cells were morphologically indistinguishable to the unexpressed cells in the other part of the periventricular germinal matrix. The expression was also seen in the hypothalamus and anterior part of the third ventricle. There was no TTF-1 positive cell identified in the caudothalamic groove in the three adult autopsy brains that we studied. 
Table 2 Summary of immunohistochemical studies of subependymal giant cell astrocytoma in the literature

\begin{tabular}{|c|c|c|c|c|c|c|c|c|c|}
\hline \multirow{2}{*}{ Publications } & \multirow{2}{*}{ Year } & \multirow{2}{*}{$\mathrm{n}$} & \multicolumn{2}{|c|}{ Glial marker (\%) } & \multicolumn{5}{|c|}{ Neuronal marker (\%) } \\
\hline & & & GFAP & $B L B P$ & Synaptophysin & Neurofilament & $\operatorname{NeuN}$ & Doublecortin & $\beta$-tubulin III \\
\hline Bonnin et $a l^{8}$ & 1984 & 22 & $19(86)$ & & & $6(27)$ & & & \\
\hline Hirose et $a l^{9}$ & 1995 & 6 & $3(50)$ & & & $2(33)$ & & & $5(83)$ \\
\hline Lopes et al ${ }^{10}$ & 1996 & 20 & $19(95)$ & & & $8(40)$ & & & $17(85)$ \\
\hline Sharma et al ${ }^{1}$ & 2004 & 23 & $23(100)$ & & $3(13)$ & $15(65)$ & & & \\
\hline Ess et $a l^{11}$ & 2005 & 8 & $4(50)$ & $8(100)$ & & & $0(0)$ & $2(25)$ & $4(50)$ \\
\hline You et $a l^{12}$ & 2005 & 8 & $8(100)$ & & $8(100)$ & $0(0)$ & $8(100)$ & & \\
\hline Buccoliero et al ${ }^{13}$ & 2009 & 9 & $9(100)$ & & $8(89)$ & $8(89)$ & & & \\
\hline Current studya & 2016 & 24 & $13(54)$ & & $5(21)$ & $5(21)$ & $0(0)$ & & \\
\hline
\end{tabular}

Abbreviations: BLBP, brain lipid-binding protein; GFAP, glial fibrillary acidic protein.

aTumor microarray materials were used in the current study, whereas whole tissue sections were used in the others.

Table 3 Immunohistochemical expression of TTF-1 (clones 8G7G3/1 and SPT24) in subependymal giant cell astrocytoma and other brain tumors

\begin{tabular}{|c|c|c|c|c|c|c|c|c|c|}
\hline & \multirow{3}{*}{$\mathrm{n}$} & \multicolumn{4}{|c|}{$8 G 7 G 3 / 1$} & \multicolumn{4}{|c|}{ SPT24 } \\
\hline & & \multirow{2}{*}{$+(\%)$} & \multicolumn{3}{|c|}{ Intensity } & \multirow{2}{*}{$+(\%)$} & \multicolumn{3}{|c|}{ Intensity } \\
\hline & & & 1 & 2 & 3 & & 1 & 2 & 3 \\
\hline Subependymal giant cell astrocytoma & 24 & $24(100)$ & 0 & 6 & 18 & $24(100)$ & 1 & 11 & 12 \\
\hline Neurocytoma & 19 & $4(21)$ & & & & $9(47)$ & & & \\
\hline Central neurocytoma & 12 & & 1 & 2 & 0 & & 4 & 2 & 0 \\
\hline Atypical neurocytoma & 7 & & 0 & 1 & 0 & & 1 & 1 & 1 \\
\hline Astrocytoma & 155 & $0(0)$ & & & & $0(0)$ & & & \\
\hline Gemistocytic astrocytoma & 21 & & 0 & 0 & 0 & & 0 & 0 & 0 \\
\hline Pleomorphic xanthoastrocytoma & 3 & & 0 & 0 & 0 & & 0 & 0 & 0 \\
\hline Diffuse astrocytoma & 45 & & 0 & 0 & 0 & & 0 & 0 & 0 \\
\hline Anaplastic astrocytoma & 46 & & 0 & 0 & 0 & & 0 & 0 & 0 \\
\hline Glioblastoma & 40 & & 0 & 0 & 0 & & 0 & 0 & 0 \\
\hline Ganglioglioma & 24 & $0(0)$ & & & & $0(0)$ & & & \\
\hline Ganglioglioma & 23 & & 0 & 0 & 0 & & 0 & 0 & 0 \\
\hline Anaplastic ganglioglioma & 1 & & 0 & 0 & 0 & & 0 & 0 & 0 \\
\hline Ependymoma & 50 & $0(0)$ & & & & $0(0)$ & & & \\
\hline Ependymoma & 27 & & 0 & 0 & 0 & & 0 & 0 & 0 \\
\hline Anaplastic ependymoma & 23 & & 0 & 0 & 0 & & 0 & 0 & 0 \\
\hline Subependymoma & 7 & $0(0)$ & 0 & 0 & 0 & $0(0)$ & 0 & 0 & 0 \\
\hline
\end{tabular}

Staining intensity: 1 , weak; 2 , moderate; 3 , strong.

\section{Mutation Status of $B R A F^{600}$}

The PCR was successfully carried out in 20 DNA samples. The other 4 DNA samples failed for the analysis were all from formalin-fixed paraffinembedded blocks of more than 10 years old, which might not be feasible for PCR due to DNA fragmentation. There was no mutation identified at the locus 600 of the BRAF gene in all the 20 samples, which included 18 tuberous sclerosis complex and 2 non-tuberous sclerosis complexassociated tumors.

\section{Discussion}

Subependymal giant cell astrocytoma is a renowned tumor in association with tuberous sclerosis complex. However, its peculiar name is not only a source of confusion, but also reflects our lack of understanding of this tumor in many ways. First, the cell origin of subependymal giant cell astrocytoma is so far unknown. Although the name infers to its origin of the 'subependymal' zone, which is a thin layer of cells with stem cell-like features along the lateral wall of lateral ventricles in the mammalian brain, ${ }^{21,22}$ it cannot explain the preferential location 

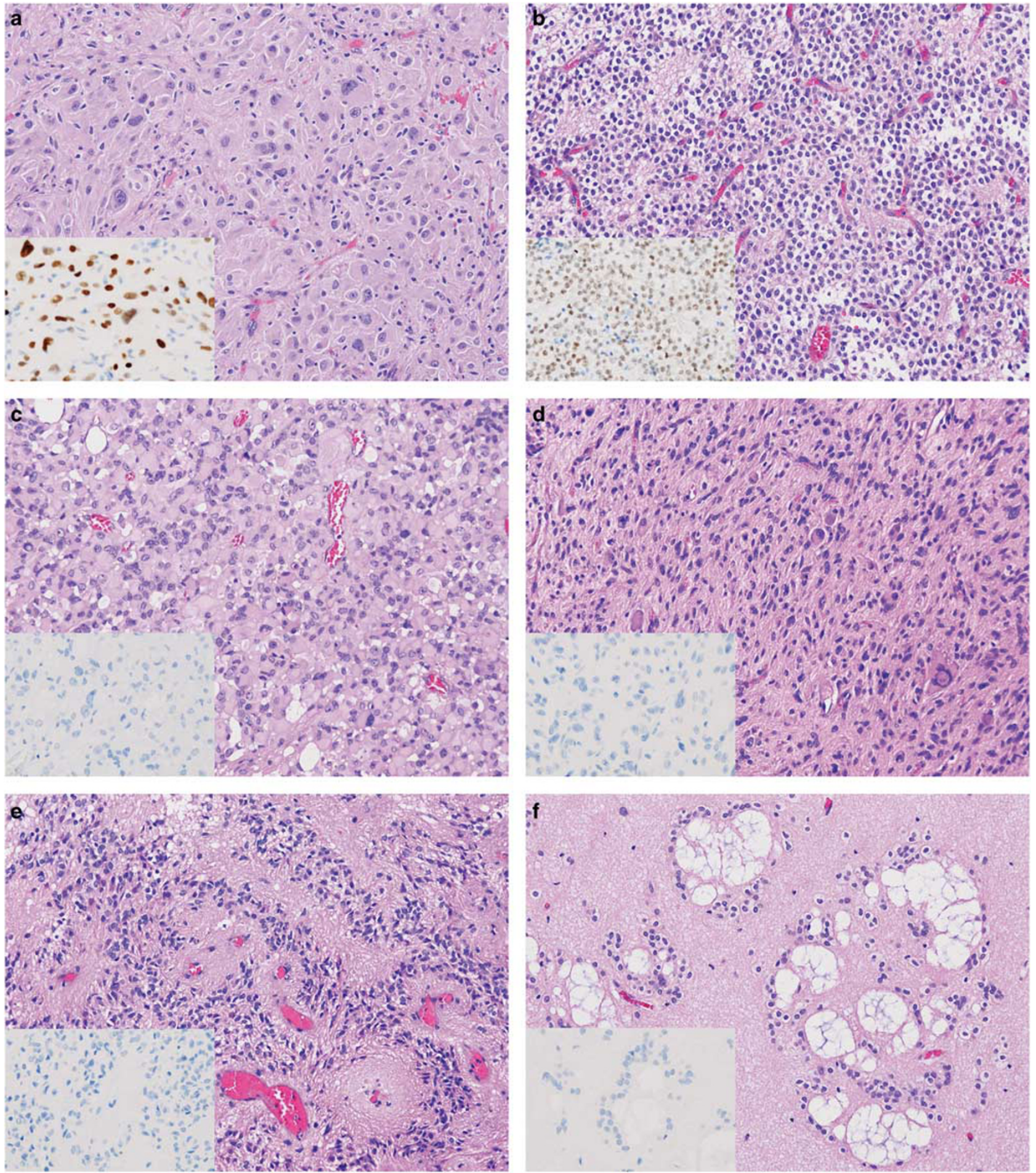

Figure 3 Immunohistochemistry for TTF-1 shows diffuse nuclear expression in subependymal giant cell tumor (a) and neurocytoma (b), whereas no nuclear staining is demonstrated in gemistocytic astrocytoma (c), ganglioglioma (d), ependymoma (e), and subependymoma (f). H\&E; insets: TTF-1. Original magnification: $\times 200$.

of caudothalamic groove of subependymal giant cell astrocytoma. Second, the term 'giant cell' is loosely defined and is also used for the giant cells in subependymal nodules as well as the dysplastic neurons or giant eosinophilic cells in the cortical tubers. $^{9,10}$ Whether these tuberous sclerosis complex-related CNS lesions morphologically resemble the giant cells in subependymal giant cell astrocytoma is because they arise from a common origin or because they share a common genetic alteration remains controversial. ${ }^{2,3,23}$ Finally, given the immunohistochemical evidence of mixed 


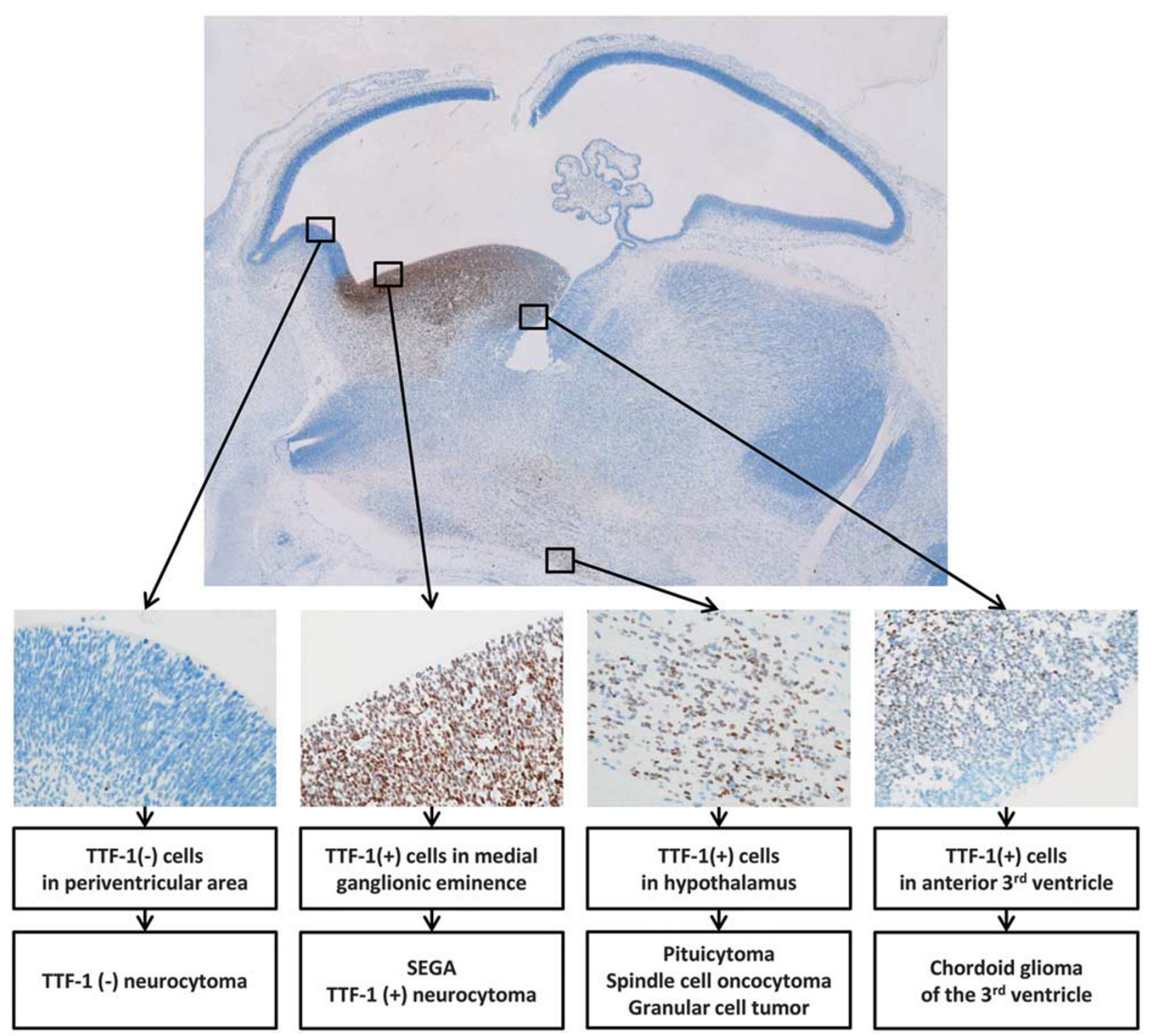

Figure 4 Proposed cell origins of TTF-1 positive brain tumors. The upper part of this diagram shows a sagittal section of a 9-week fetal brain stained for TTF-1. The four photos in the second row show higher magnification of the corresponding areas in the whole-mount photo. The TTF-1 expression is seen in the ependymal cells and subependymal progenitor cells in the medial ganglionic eminence adjacent to the foramen of Monro as well as cells in the hypothalamus and the anterior part of the third ventricle. The TTF-1 positive and TTF-1 negative periventricular germinal matrix cells are morphologically indistinguishable. We propose that subependymal giant cell astrocytoma is derived from the TTF-1 positive progenitor cells in the medial ganglionic eminence. These cells may also give rise to the TTF-1 positive neurocytoma. The other TTF-1 positive tumors, eg, pituicytoma, spindle cell oncocytoma, granular cell tumor of the sellar region, and chordoid glioma of the third ventricle, are from either the hypothalamus/neurohypophysis or the anterior part of the third ventricle.

glioneuronal differentiation of this tumor, the classification of subependymal giant cell astrocytoma as an 'astrocytoma' may not be appropriate. ${ }^{1,8-13}$

In most of the subependymal giant cell astrocytomas, the giant cell feature is fairly eye-catching. However, the tumor is also composed of other cell types, including gemistocyte-like cells and spindle cells. The predominance of one cell type or the mixture of different cell types in various proportions would raise different differential diagnoses. The main differential diagnoses include gemistocytic astrocytoma when the gemistocyte-like cells are predominant and ganglioglioma when there is a mixture of ganglion-like giant cells and spindle cells. The distinction between these tumors solely depends on morphology as the conventional glial and neuronal markers such as GFAP and synaptophysin have little role in this setting. Furthermore, occasional presence of atypical features in subependymal giant cell astrocytoma may cause confusion with other higher-grade brain tumors. In this study, tumor necrosis was seen in 4/26 (15\%) of cases. 
Although not present in our series, other atypical features such as endothelial proliferation and increased in mitotic activity have been welldocumented. ${ }^{1,6,7}$ However, none of these atypical features are associated with an adverse outcome. Therefore, one should take extra caution with subependymal giant cell astrocytoma showing these atypical features and not overdiagnose it as glioblastoma. In addition, perivascular pseudorosettes are also very common in subependymal giant cell astrocytoma. It occurred in 11/26 (42\%) of our cases and may need to be differentiated from an ependymoma. Immunohistochemistry for epithelial membrane antigen may help distinguish these two tumors. As the staining pattern in subependymal giant cell astrocytoma is membranous and in focal clusters, ${ }^{15}$ but dot-like and microluminal in an ependymoma.

TTF-1 is a $38 \mathrm{kDa}$ DNA-binding protein encoded by a homeobox gene NKX2-1 located on chromosome $14 \mathrm{q} 13 .{ }^{24}$ It has an important role in the development of the thyroid, lung, ventral forebrain, and pituitary gland. ${ }^{25,26}$ In pathological practice, immunohistochemistry for TTF-1 is commonly used as a linage-specific marker for tumors of thyroid or lung origin. ${ }^{27}$ There are two different clones of antiTTF-1 antibody, 8G7G3/1 and SPT24, and the former is believed to be more specific. ${ }^{28}$ In a large survey of 155 primary CNS tumors, none of them showed TTF-1 expression using clone 8G7G3/1. In contrast, TTF-1 expression using clone SPT24 was found in a few cases, including anaplastic astrocytoma (1/13), anaplastic oligodendroglioma (3/7), glioblastoma (6/36), central neurocytoma (1/3), ependymoma (1/12), and choroid plexus carcinoma (1/2). ${ }^{29} \mathrm{In}$ another report, patchy TTF-1 staining (ranging from 0.1 to $62.2 \%$ of nuclei) was noted in 14 out of 28 glioblastomas using clone SPT24, and none was reactive using clone $8 \mathrm{G} 7 \mathrm{G} 3 / 1 .{ }^{30}$ Accordingly, although focal staining could be seen using the less specific clone SPT24, TTF-1 expression in the primary CNS tumors was thought to be largely negative using clone $8 \mathrm{G} 7 \mathrm{G} 3 / 1$.

Recently, several distinct CNS tumors arising from specific locations of the human brain have been shown to express TTF-1, including pituicytoma, spindle cell oncocytoma, granular cell tumor of the sellar region, and chordoid glioma of the third ventricle. $^{31-34}$ In 2015, two groups independaently reported diffuse TTF-1 expression in 4 and 7 subependymal giant cell astrocytomas. ${ }^{14,15}$ Following these studies, we confirmed diffuse TTF-1 expression in all 24 subependymal giant cell astrocytoma specimens using two different clones of antibodies. For the other brain tumors that we studied, only neurocytomas showed TTF-1 expression, with a lower percentage using the more specific clone $8 \mathrm{G} 7 \mathrm{G} 3 / 1(4 / 19,21 \%)$ compared with the less specific clone SPT24 (9/19, 47\%).

Through the embryological development of the brain, TTF-1 expression has been demonstrated in the neurohypophysis, the ventral hypothalamic area spanning from the floor of the third ventricle to the sulcus diencephalicus ventralis, and the floor of the telencephalic vesicles restricted to the medial ganglionic eminence. ${ }^{25}$ Our study on three fetal brains confirmed this finding. Medial ganglionic eminence is a part of germinal matrix and a transient fetal structure between the caudate nucleus and the thalami during neurodevelopment. ${ }^{35}$ The majority of progenitor cells in medial ganglionic eminence express TTF-1, which controls migration and sorting of interneurons to the striatum or cortex, and is required for interneuron subtype specification. ${ }^{36,37}$ The structure would completely disappear before the age of one. This may explain the absence of TTF-1 expressing cells in the caudothalamic groove in our adult autopsy brains. In other areas of the brain, TTF-1 expression have been reported strong in the posterior pituitary gland and faint in the lamina terminalis in both fetal and adult human brain tissues. ${ }^{31,34}$ Similar expression patterns have also been reported in rat brains. ${ }^{25,38,39}$

In a study on intraventricular lesions in 103 tuberous sclerosis complex patients, of which 22 had more than 4 years of neuroimaging follow-up, it was concluded that although intraventricular lesions occurred through the lateral ventricular wall, only those located at the caudothalamic groove had the potential to grow and all the resected lesions from this location were pathologically proven as subependymal giant cell astrocytomas. ${ }^{2}$ Our neuroimaging review concurred with this result as all subependymal giant cell astrocytomas including three without clinical evidence of tuberous sclerosis complex arose from the area of caudothalamic groove. Coupling with the immunohistochemical and radiological findings, we propose that subependymal giant cell astrocytoma arises from nondisappearing TTF-1 positive progenitor cells of medial ganglionic eminence in the caudothalamic groove. The other TTF-1 positive brain tumors as mentioned earlier are from either the hypothalamus/ neurohypophysis or the anterior third ventricle (Figure 4). Tumors arising outside of these locations are inevitably TTF-1 negative. In our comparison study of histologic and locational mimics of subependymal giant cell astrocytoma, neurocytoma was the only tumor showing TTF-1 expression in a portion of the cases. The radiological review of our neurocytomas, showing that all nine TTF-1 positive neurocytomas had at least partial attachment to the caudothalamic groove, whereas all the four neurocytomas without any attachment to this region were TTF-1 negative, aligned with this observation. Neurocytoma arising from this region may also originate from progenitor cells of medial ganglionic eminence and obtain TTF-1 expression; however, the histomorphology of neurocytoma is substantially different and unlikely to be confused with subependymal giant cell astrocytoma. Although all ependymomas in our series were TTF-1 negative, others 
have reported two ependymomas arising from the third ventricle, which express TTF-1 using the more specific clone $8 \mathrm{G} 7 \mathrm{G} 3 / 1 .{ }^{40}$ A study of one cortical tuber, a tuberous sclerosis complex-associated hamartomatous brain lesion comprising dysplastic neurons and giant eosinophilic cells, showed absence of TTF-1 expression and suggested a possibly different cell origin from subependymal giant cell astrocytoma despite the morphological similarity. ${ }^{14}$

The $B R A F^{\mathrm{V} 600 \mathrm{E}}$ mutation was first reported in 1 out of 3 subependymal giant cell astrocytomas in a large molecular survey of primary CNS tumors. ${ }^{16}$ The mutated tumor was from the temporal lobe of a 59 year-old male without clinical features of tuberous sclerosis complex and the recurrent tumor at the same location was an ependymoma. In another study, a significant portion $(6 / 14,42.9 \%)$ of subependymal giant cell astrocytomas harboring $B R A F^{V 600 \mathrm{E}}$ mutation was found using direct sequencing method. ${ }^{19}$ This mutation was not demonstrated in the $20 \mathrm{TTF}-1$ positive subependymal giant cell astrocytomas that we studied. The mutation status of $B R A F$ gene in subependymal giant cell astrocytoma remains to be clarified in further studies.

In conclusion, TTF-1 is a useful marker in distinguishing subependymal giant cell astrocytoma from its histologic mimics, in particular gemistocytic astrocytoma and ganglioglioma. Neurocytoma is the other tumor frequently reactive for TTF-1 in the ventricular system. On the basis of the expression of TTF-1 in medial ganglionic eminence of the fetal brains and the radiological evidence of all subependymal giant cell astrocytomas arising from the region of caudothalamic groove, we propose that the progenitor cells capable of glial and neuronal differentiation in this area are the cell origin of subependymal giant cell astrocytoma. There was no $B R A F^{\mathrm{V} 600 \mathrm{E}}$ mutation identified in the 20 subependymal giant cell astrocytomas that we studied.

\section{Acknowledgments}

We thank Hsiang-Ling Ho, $\mathrm{PhD}$ for technical assistance and Jimmy Lee, MD for English editing. This study was sponsored by research grants from the Taipei Veterans General Hospital (V105A-015, V105C-185, and V105C-187).

\section{Disclosure/conflict of interest}

The authors declare no conflict of interest.

\section{References}

1 Sharma MC, Ralte AM, Gaekwad S, et al. Subependymal giant cell astrocytoma-a clinicopathological study of 23 cases with special emphasis on histogenesis. Pathol Oncol Res 2004;10:219-224.
2 Katz JS, Milla SS, Wiggins GC, et al. Intraventricular lesions in tuberous sclerosis complex: a possible association with the caudate nucleus. J Neurosurg Pediatr 2012;9:406-413.

3 Roth J, Roach ES, Bartels U, et al. Subependymal giant cell astrocytoma: diagnosis, screening, and treatment. Recommendations from the International Tuberous Sclerosis Complex Consensus Conference 2012. Pediatr Neurol 2013;49:439-444.

4 Hyman $\mathrm{MH}$, Whittemore VH. National Institutes of Health consensus conference: tuberous sclerosis complex. Arch Neurol 2000;57:662-665.

5 Franz DN, Belousova E, Sparagana S, et al. Efficacy and safety of everolimus for subependymal giant cell astrocytomas associated with tuberous sclerosis complex (EXIST-1): a multicentre, randomised, placebo-controlled phase 3 trial. Lancet 2013;381: 125-132.

6 Shepherd CW, Scheithauer BW, Gomez MR, et al. Subependymal giant cell astrocytoma: a clinical, pathological, and flow cytometric study. Neurosurgery 1991;28:864-868.

7 Grajkowska W, Kotulska K, Jurkiewicz E, et al. Subependymal giant cell astrocytomas with atypical histological features mimicking malignant gliomas. Folia Neuropathol 2011;49:39-46.

8 Bonnin JM, Rubinstein LJ, Papasozomenos SC, et al. Subependymal giant cell astrocytoma. Significance and possible cytogenetic implications of an immunohistochemical study. Acta Neuropathol 1984;62: 185-193.

9 Hirose T, Scheithauer BW, Lopes MB, et al. Tuber and subependymal giant cell astrocytoma associated with tuberous sclerosis: an immunohistochemical, ultrastructural, and immunoelectron and microscopic study. Acta Neuropathol 1995;90:387-399.

10 Lopes MB, Altermatt HJ, Scheithauer BW, et al. Immunohistochemical characterization of subependymal giant cell astrocytomas. Acta Neuropathol 1996;91: 368-375.

11 Ess KC, Kamp CA, Tu BP, et al. Developmental origin of subependymal giant cell astrocytoma in tuberous sclerosis complex. Neurology 2005;64:1446-1449.

12 You H, Kim YI, Im SY, et al. Immunohistochemical study of central neurocytoma, subependymoma, and subependymal giant cell astrocytoma. J Neurooncol 2005;74:1-8.

13 Buccoliero AM, Franchi A, Castiglione F, et al. Subependymal giant cell astrocytoma (SEGA): is it an astrocytoma? Morphological, immunohistochemical and ultrastructural study. Neuropathology 2009;29: 25-30.

14 Hewer E, Vajtai I. Consistent nuclear expression of thyroid transcription factor 1 in subependymal giant cell astrocytomas suggests lineage-restricted histogenesis. Clin Neuropathol 2015;34:128-131.

15 Chatzopoulos $\mathrm{K}$, Koletsa $\mathrm{T}$, Iliadis $\mathrm{A}$, et al. Thyroid transcription factor-1 and epithelial membrane antigen expression in four cases of subependymal giant cell astrocytoma. Histopathology 2015;66: 1035-1036.

16 Schindler G, Capper D, Meyer J, et al. Analysis of BRAF V600E mutation in 1,320 nervous system tumors reveals high mutation frequencies in pleomorphic xanthoastrocytoma, ganglioglioma and extra-cerebellar pilocytic astrocytoma. Acta Neuropathol 2011;121: 397-405. 
17 Chappe C, Padovani L, Scavarda D, et al. Dysembryoplastic neuroepithelial tumors share with pleomorphic xanthoastrocytomas and gangliogliomas BRAF(V600E) mutation and expression. Brain Pathol 2013;23: $574-583$

18 Prabowo AS, Iyer AM, Veersema TJ, et al. BRAF V600E mutation is associated with mTOR signaling activation in glioneuronal tumors. Brain Pathol 2014;24:52-66.

19 Lee D, Cho YH, Kang SY, et al. BRAF V600E mutations are frequent in dysembryoplastic neuroepithelial tumors and subependymal giant cell astrocytomas. J Surg Oncol 2015;111:359-364.

20 Hang JF, Li AF, Chang SC, et al. Immunohistochemical detection of BRAF V600E mutant protein in colorectal cancers in Taiwan is highly concordant with the molecular test. Histopathology 2015;69:54-62.

21 Quinones-Hinojosa A, Chaichana K. The human subventricular zone: a source of new cells and a potential source of brain tumors. Exp Neurol 2007;205:313-324.

22 Zhou J, Shrikhande G, Xu J, et al. Tsc1 mutant neural stem/progenitor cells exhibit migration deficits and give rise to subependymal lesions in the lateral ventricle. Genes Dev 2011;25:1595-1600.

23 Crino PB, Nathanson KL, Henske EP. The tuberous sclerosis complex. N Engl J Med 2006;355:1345-1356.

24 Guazzi S, Price M, De Felice M, et al. Thyroid nuclear factor 1 (TTF-1) contains a homeodomain and displays a novel DNA binding specificity. EMBO J 1990;9: 3631-3639.

25 Lazzaro D, Price M, de Felice M, et al. The transcription factor TTF-1 is expressed at the onset of thyroid and lung morphogenesis and in restricted regions of the foetal brain. Development 1991;113:1093-1104.

26 Kimura S, Hara Y, Pineau T, et al. The T/ebp null mouse: thyroid-specific enhancer-binding protein is essential for the organogenesis of the thyroid, lung, ventral forebrain, and pituitary. Genes Dev 1996;10: $60-69$.

27 Ordonez NG. Thyroid transcription factor-1 is a marker of lung and thyroid carcinomas. Adv Anat Pathol 2000;7:123-127.

28 Matoso A, Singh K, Jacob R, et al. Comparison of thyroid transcription factor-1 expression by 2 monoclonal antibodies in pulmonary and nonpulmonary primary tumors. Appl Immunohistochem Mol Morphol 2010;18:142-149.

29 Kristensen $\mathrm{MH}$, Nielsen S, Vyberg M. Thyroid transcription factor-1 in primary CNS tumors. Appl Immunohistochem Mol Morphol 2011;19:437-443.

30 Galloway M, Sim R. TTF-1 staining in glioblastoma multiforme. Virchows Arch 2007;451:109-111.

31 Lee EB, Tihan T, Scheithauer BW, et al. Thyroid transcription factor 1 expression in sellar tumors: a histogenetic marker? J Neuropathol Exp Neurol 2009;68:482-488.

32 Mete O, Lopes MB, Asa SL. Spindle cell oncocytomas and granular cell tumors of the pituitary are variants of pituicytoma. Am J Surg Pathol 2013;37:1694-1699.

33 Michotte A, Van Der Veken J, Huylebrouck M, et al. Expression of thyroid transcription factor 1 in a chordoid glioma. J Neurol Sci 2014;346:362-363.

34 Bielle F, Villa C, Giry M, et al. Chordoid gliomas of the third ventricle share TTF-1 expression with organum vasculosum of the lamina terminalis. Am J Surg Pathol 2015;39:948-956.

35 Encha-Razavi F, Sonigo P. Features of the developing brain. Childs Nerv Syst 2003;19:426-428.

36 Nobrega-Pereira S, Kessaris N, Du T, et al. Postmitotic Nkx2-1 controls the migration of telencephalic interneurons by direct repression of guidance receptors. Neuron 2008;59:733-745.

37 Butt SJ, Sousa VH, Fuccillo MV, et al. The requirement of Nkx2-1 in the temporal specification of cortical interneuron subtypes. Neuron 2008;59:722-732.

38 Lee BJ, Cho GJ, Norgren RB Jr, et al. TTF-1, a homeodomain gene required for diencephalic morphogenesis, is postnatally expressed in the neuroendocrine brain in a developmentally regulated and cell-specific fashion. Mol Cell Neurosci 2001;17: 107-126.

39 Flandin P, Kimura S, Rubenstein JL. The progenitor zone of the ventral medial ganglionic eminence requires Nkx2-1 to generate most of the globus pallidus but few neocortical interneurons. J Neurosci 2010;30: 2812-2823.

40 Zamecnik J, Chanova M, Kodet R. Expression of thyroid transcription factor 1 in primary brain tumours. J Clin Pathol 2004;57:1111-1113. 